\title{
PENGAWETAN DUA JENIS KAYU BENTUKAN DENGAN BAHAN PENGAWET BFCA SECARA RENDAMAN DINGIN \\ (Cold Soaking Treatment of Two Wood Species of Moulding Products Using BFCA Preservative)
}

\author{
Oleh/By \\ Sasa Abdurrohim dan Bakir Ginoga
}

Summary

Moulding products made of two wood species in the form of coves were treated with BFCA preservative by cold soaking. The length of the test pieces were $30 \mathrm{~cm}$. The duration of cold soaking treatment were 2, 4, 6 and 8 days, with preservative concentrations of 5 and 10 percent.

The test results, after taking both retention and penetration requirements into consideration for wood uses under roof and in the open air without ground contact, showed that both wood species could be satisfactorily treated under experimental conditions. The treatment schedules proposed for both species are also presented in this paper.

The average swelling of those species after treatment comparing to dimension are relatively small, therefore could be avaidable and has no affect on their use.

\section{PENDAHULUAN}

Kayu sebagai bahan baku industri bentukan (moulding) diduga sebagian besar terdiri dari jenis-jenis kurang atau tidak awet, yaitu kelas awet III sampai V. Pemakaian jenis-jenis ini dikhawatirkan merupakan beban bagi pemakainya karena mudah rusak dalam waktu yang relatif singkat. Untuk mengatasinya, dalam proses pembuatan bentukan dengan bahan baku dari jenis-jenis kayu tidak atau kurang awet itu perlu melibatkan pengawetan.

Sudah diketahui bahwa hasil pengawetan bergantung kepada jenis kayu yang diawetkan, bahan pengawet yang digunakan dan cara pengawetan yang dilakukan. Jenis kayu berpengaruh terhadap keterawetan kayu, yaitu ada jenis kayu yang mudah dan ada yang sukar dimasuki bahan pengawet. Jenis bahan pengawet untuk kayu yang digunakan dalam ruangan berbeda dengan yang akan digunakan di luar, sehingga pemilihan jenis bahan pengawet juga berpengaruh terhadap cara pengawetan, agar tercapai penetrasi yang dalam dan retensi bahan pengawet yang sesuai dengan dosisnya.

Permasalahan yang timbul dalam mengawetkan kayu bentukan adalah di mana proses pengawetan seharusnya dilakukan. Apabila pengawetan dilakukan sebelum kayu dikeringkan, maka dalam proses pembuatan bentukan bagian yang dimasuki bahan pengawet dengan retensi tinggi akan terbuang akibat penyerutan, sehingga hal ini tidak memungkinkan dilakukan. Jika diawetkan setelah menjadi bentukan diduga kayu akan basah dan mengembang kembali. Apabila pengembangan relatif besar diperlukan pengeringan kembali, yang dengan sendirinya makin meningkatkan biaya produksi. Untuk itu perlu diketahui besar pengembangan yang terjadi akibat perlakuan pengawetan.

Dalam makalah ini disajikan hasil pengawetan dua jenis kayu Kalimantan Timur yang telah menjadi bentukan, berupa lis (coves, crown/beds), yaitu nyatoh (Palaquium sp.) dan perupuk (Solenospermum sp.), secara rendaman dingin menggunakan bahan pengawet golongan BFCA.

\section{BAHAN DAN METODE}

Kayu yang digunakan terdiri dari dua jenis yang berasal dari Kalimantan Timur, yaitu nyatoh (Palaquium sp.) dan perupuk (Solenospermum sp.), dengan kadar air rata-rata masing-masing 11,9 dan 14,2 persen. Penyusutan sampai kering udara, kelas kuat dan kelas awet kedua jenis kayu tercantum dalam Tabel I.

Dari setiap jenis kayu kering udara dibuat bentukan (moulding), berupa lis. Pada bidang melintang dan sejajar sumbu batang diusahakan agar lingkaran tahun pada setiap contoh uji masing-masing membentuk sudut $45^{\circ}$ dan sejajar sisinya. Selanjutnya dari setiap jenis dibuat 40 buah contoh uji dengan panjang $30 \mathrm{~cm}$. Tebal dan lebar contoh uji nyatóh masing-masing kurang lebih $20,7 \mathrm{~mm}$ dan 35,7 mm, sedangkan contoh uji perupuk masing-masing 26,2 $\mathrm{mm}$ dan $80,2 \mathrm{~mm}$. Dari setiap jenis disediakan pula 10 buah contoh uji dengan panjang tiga $\mathrm{cm}$ untuk mengukur berat jenis kayu kering udara.

Bahan pengawet yang digunakan adalah satu jenis golongan BFCA dengan komposisi terdiri dari $\mathrm{Na}_{2} \mathrm{~B}_{4} 0_{7}$. $5 \mathrm{H}_{2} \mathrm{O}, \mathrm{H}_{3} \mathrm{BO}_{3}, \mathrm{NaF}, \mathrm{As}_{2} \mathrm{O}_{5} .2 \mathrm{H}_{2} \mathrm{O}$ dan $\mathrm{Na}_{2} \mathrm{Cr}_{2} \mathrm{O}_{7} .2 \mathrm{H}_{2} \mathrm{O}$, masing-masing dengan kandungan 25,40,15,11 dan 9 persen (Martawijaya dan Abdurrohim,1984; Standar Kehutanan Indonesia, 1987). Bentuk formulasinya adalah bubuk yang mengandung 100 persen bahan aktif garam.

Kedua ujung setiap contoh uji ditutup cat duco untuk mencegah masuknya bahan pengawet dari arah longitudinal, dan kemudian ditimbang. Selain ditimbang, tebal dan lebar setiap contoh uji diukur memakai jangka sorong (dial calyper). 
Tabed 1. Penyusutan, Kelas Kuat dan Kelas Awet Kayu yang Diteliti

Table 1. Shrinkage, Strength and Durability Classes of Treated Wood Species

\begin{tabular}{|c|c|c|c|c|}
\hline Jenie kaya & Pony & ring udara & +4 & \\
\hline (Wood spectes) & $\begin{array}{r}\text { Radial } \\
\text { (Radial) }\end{array}$ & $\begin{array}{l}\text { Tangensial } \\
\text { (Tangential) }\end{array}$ & $\begin{array}{c}\text { Kuat } \\
\text { (Strength) }\end{array}$ & $\begin{array}{c}\text { Awet } \\
\text { (Durability) }\end{array}$ \\
\hline $\begin{array}{l}\text { Nyctols (Palaquivem ep.) } \\
\text { Perupulk (Solenaspermum sp.) }\end{array}$ & $\begin{array}{l}2,4 \\
1,3\end{array}$ & $\begin{array}{l}3,0 \\
2,7\end{array}$ & $\begin{array}{l}\text { II - III } \\
\text { III - IV }\end{array}$ & $\begin{array}{r}\text { III - IV 1) } \\
v^{2)}\end{array}$ \\
\hline
\end{tabular}

Sumber (Sounce) : 1) Martawijaya et al., (1981)

2) Martawijaya et al., (1989)

Setiap 20 contoh uji dari setiap jenis kayu diawetkan socara rendaman dingin memakai bahan pengawet BFCA tersobut di atas pada konsentrasi lima dan sepuluh persen. Lama rendaman yang digunakan adalah dua, empat, enam den delapen hari, sehingga untuk setiap lama rendaman disediakan lima contoh uji sobagai ulangan. Setelah diawetkan sesuai lama rendamannya, setiap contoh uji ditimbang dan diukur kembali.

Retensi bahan pengawet setiap contoh uji dihitung dengan cara berikut :

$$
\mathbf{R}=\frac{\mathbf{B}}{\mathbf{V}} \times \mathrm{K} \ldots \ldots \ldots \ldots \ldots \ldots \ldots \ldots \ldots \ldots \ldots \ldots
$$

dan

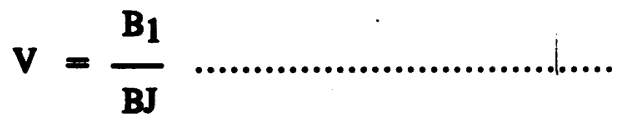

di mana $\mathbf{R}=$ retensi bahan pengawet $\left(\mathbf{k g} / \mathbf{m}^{3}\right), B=$ selisih berat contoh uji sobelum dan sosudah diawetkan $(\mathbf{k g}), \mathrm{V}=$ volume contoh uji $\left(\mathrm{m}^{3}\right), \mathrm{K}=$ konsentrasi larutan bahan pengawet (\%), B1 = berat contoh uji sebelum diawetkan den $B j=$ berat jenis.

Pengembangan (swelling) setiap contoh uji dihitung dengan cara berikut :

$$
S_{t}=\frac{T_{1}-T_{2}}{T_{1}} \times 100
$$

dan

$$
s_{1}=\frac{L_{1}-L_{2}}{L_{1}} \times 100
$$

di $\operatorname{mana}$ St $=$ pengembangen tebal $(\%), T 1=$ tebal sobolum diawetkan $(\mathrm{mm}), \mathbf{T 2}=$ tobal sesudah diawetkan $(\mathrm{mm}), \mathrm{S1}=$ pengermbengen lobar $(\%), \mathrm{L1}=$ lebar sobolum diawolken (mm) dan 'L2 = lebar' sesudah diawetkan (mm).

Untuk mengukur dalamnya penetrasi bahan pengawet, sotiap contoh uji dipotong pada bagian tengahnya, setelah dua mingsu dibiarkan pada suhu kamar sejak selesai pengawetan. Pada alah satu bidang potong dilaburkan dua macam poreaksi, yaitu :
Pereaksi $A=2$ gr ekstrak kurkuma dalam $100 \mathrm{ml}$ alkohol Pereaksi $B=20 \mathrm{ml}$ alkohol $+30 \mathrm{ml} \mathrm{HCl}$ yang dijénuhkan dengan asam salisilat.

Adanya penembusan boron ditunjukan oleh perubahan warna menjadi merah jambu. Penetrasi pada potongan melintang contoh uji dinyatakan dalam persentase luas permukaan yang ditembus bahan pengawet.

Analisis data untuk melihat pengaruh jenis kayu, konsentrasi larutan dalam jenis kayu yang sama, serta lama rendaman dingin dalam jenis kayu dan konsentrasi larutan yang sama, terhadap retensi dan penetrasi bahan pengawet digunakan klasifikasi tersarang (Steel dan Torrie, 1960). Apabila jenis kayu,konsentrasi larutan dalam jenis kayu yang sama, serta lama rendaman dingin dalam jenis kayu dan konsentrasi larutan yang sama, berpengaruh nyata terhadap retensi dan penetrasi,maka harga rata-ratanya dibandingkan dengan nilai beda nyata jujur memakai prosedur Tukey.

Untuk menentukan bagan pengawetan yang dianjurkan, hasil retensi dan penetrasi setiap contoh uji dari suatu bagan pengawetan harus memenuhi persyaratan minimum. nya. Apabila dalam setiap jenis kayu diperoleh lebih dari satu bagan pengawetan yang mencapai persyaratan minimum retensi dan penetrasi, maka bagan pengawetan yang dianjurkan adalah dengan lama rendaman terpendek.

Terhadap pengembangan (swelling), pengaruh sumber. keragaman tidak dianalisis tetapi hanya dihitung rata-rata pengembangan pada setiap bagan pengawetan. Selanjutnya rata-rata ini dinilai apakah relatif besar atau kecil pengembangannya dibandingkan ukuran melintang contoh uji.

\section{HASIL DAN PEMBAHASAN}

Hasil pengamatin retensi idin penetrasi bahan pengaivet BFCA pada dua jenis kayu, sertri pengembingan ke arah. tebal dan lebar, tercantum dalam Tabel 2. Dalam tabel dapat dilihat bahwa penetrasi bahan pengawet BFCA pada semua contoh uji mencapai 100 persen, yang berarti semua potongan melintang contoh uji secara mudah dapat ditembus bahan pengawet tersebut.

Sidik ragam retensi bahan pengawet BFCA tercantum 
Tabel 2. Hasil Pengamatan Retensi dan Penetrasi Bahan Pengawet BFCA serta Pengembangan Dun Jenis Kayu Bentukan yang Diavretkan Secara Rendaman Dingin (Rata-rata dari lima ulangan)

Table 2. Retention and Penetration BFCA Proservative, and Swolling of Two Moulding Wood Species with Treated by Cold Soaking Process (Mean Value of five replicaition)

\begin{tabular}{|c|c|c|c|c|c|c|}
\hline \multirow{2}{*}{$\begin{array}{l}\text { Jenis kayu } \\
\text { (Wood spectes) }\end{array}$} & \multirow{2}{*}{$\begin{array}{l}\text { Konsentrasi } \\
\text { (Concentration) } \\
\%\end{array}$} & \multirow{2}{*}{$\begin{array}{l}\text { Lama rendaman } \\
\text { (Cold soaking period) } \\
\text { hari (day) }\end{array}$} & \multirow{2}{*}{$\begin{array}{l}\text { Retensi } \\
\text { (Retentign) } \\
\mathrm{kg} / \mathrm{m}^{3}\end{array}$} & \multirow{2}{*}{$\begin{array}{l}\text { Penetrasi } \\
\text { (Penetration) } \\
\%\end{array}$} & \multicolumn{2}{|c|}{ Pengembangan (Swelling) } \\
\hline & & & & & $\begin{array}{c}\text { Tebal } \\
\text { (Thichersts) }\end{array}$ & $\begin{array}{l}\text { Lebar } \\
\text { (Wdah) }\end{array}$ \\
\hline Nyatoh (Palaguibum rp.) & $5-$ & $\begin{array}{l}2 \\
4 \\
6 \\
8\end{array}$ & $\begin{array}{r}3,3 \\
4,6 \\
5,8 \\
\times 6,0\end{array}$ & $\begin{array}{l}100 \\
100 \\
100 \\
100\end{array}$ & $\begin{array}{l}2,0 \\
1,8 \\
1,9 \\
2,0\end{array}$ & $\begin{array}{l}2,8 \\
2,5 \\
2,0 \\
2,6\end{array}$ \\
\hline \multirow[t]{3}{*}{$\cdot$} & Rata-rata (Mean) & & 4,9 & 100 & 1,9 & 2,5 \\
\hline & 10 & $\begin{array}{l}2 \\
4 \\
6 \\
8\end{array}$ & $\begin{array}{r}7,1 \\
7,8 \\
9,6 \\
10,6\end{array}$ & $\begin{array}{l}100 \\
100 \\
100 \\
100\end{array}$ & $\begin{array}{l}1,8 \\
1,9 \\
2,1 \\
2,0\end{array}$ & $\begin{array}{l}2,5 \\
2,2 \\
2,6 \\
2,5\end{array}$ \\
\hline & Rata-rata $(M$ & ean) & 8,8 & 100 & 2,0 & 2,5 \\
\hline Rata-rata (Mean) & & & 6,9 & 100 & $1,9:$ & 2,5 \\
\hline \multirow[t]{4}{*}{ Porrpuk (Solenospertivin ep.) } & 5 & $\begin{array}{l}2 \\
4 \\
6 \\
8\end{array}$ & $\begin{array}{l}5,1 \\
6,2 \\
8,1 \\
9,8\end{array}$ & $\begin{array}{l}100 \\
100 \\
100 \\
100\end{array}$ & $\begin{array}{l}0,9 \\
1,8 \\
1,6 \\
1,4\end{array}$ & $\begin{array}{l}2,1 \\
2,1 \\
1,7 \\
2,0\end{array}$ \\
\hline & Rata-rata (Mean) & & 7,3 & 100 & 1,4 & 2,0 \\
\hline & 10 & $\begin{array}{l}2 \\
4 \\
6 \\
8\end{array}$ & $\begin{array}{r}6,8 \\
11,8 \\
16,0 \\
18,1\end{array}$ & $\begin{array}{l}100 \\
100 \\
100 \\
100\end{array}$ & $\begin{array}{l}1,1 \\
1,4 \\
1,2 \\
1,3\end{array}$ & $\begin{array}{l}2,1 \\
2,4 \\
2,2 \\
2,0\end{array}$ \\
\hline & Rata-rati (Mean) & & 13,2 & 100 & 1,3 & 2,2 \\
\hline Ratn-rata (Mean) & & & 10,3 & 100 & 1,3 & 2,1 \\
\hline
\end{tabular}

Tabel 3. Sidik Ragam Retensi Bahan Pengawet BFCA

Table 3. Analysts of Vartance for BFCA Retention

\begin{tabular}{|c|c|c|c|}
\hline Sumber keragaman (Source of variation) & $\begin{array}{l}\text { Db } \\
\text { (DS) }\end{array}$ & $\begin{array}{l}\text { Kuadrat tengah } \\
\text { (Mean square) }\end{array}$ & $\begin{array}{l}\text { Fhit. } \\
\text { (Fcalc.) }\end{array}$ \\
\hline Jenis kayu (Wood spectes) & 1 & 231,2 & 0,93 \\
\hline Konwentrasi larutan delam jentis kayu yang sama (Concentration within the same wood species) & 2 & 247,630425 & $5,98 *$ \\
\hline $\begin{array}{l}\text { Lama rendaman dingin dalam jenis kayu dan konsentrasi yang sama } \\
\text { (Cold soaldng pertod whath the same wood species and concentration). }\end{array}$ & 12 & 41,39291666 & $9,22 * *$ \\
\hline Ulangan dalam lama rondamian dingin yang sama (Replication whthin the cold soaking period) & 64 & & \\
\hline Jumlah (Toral) & 79 & & , \\
\hline
\end{tabular}

- Sangat nyata (Fighty stenticani)

dalam Tabel 3. Dalam tabel dapat dilihat bahwa jenis kayu tidak berpengaruh nyata terhadap retehsi bahan pengawet BFCA. Konsentrasi larutan dalam jenis kayu yang sama berpengaruh nyata terhadap retensi bahan pengawet BFCA, sodangkan lama rendaman dingin dalam jenis kayu dan konsentrasi larutan yang sama memunjuldkan pengaruh sangat nyata. Nilai boda nyata jujur retensi bahan pengawet BFCA pada tingkat nyata lima persen $\left(\mathrm{W}_{0,05)}\right.$ untuk komsentrasi larutan dalam jenis kayu yang sama, sorta untuk lama rendaman dingin dalam jenis kayu dan konsentrasi larutan yang sama, masing-masing $4,4 \mathrm{~kg} / \mathrm{m}^{3}$ dan $3,5 \mathrm{~kg} / \mathrm{m}^{3}$.

Peningkatan konsentrasi larutan bahan pengawet dari lima persen menjadi sepuluh persen pada kayu perupuk (Solenospermum sp.) dapat meningkatkan retensi bahan pengawet BFCA dengan perbedaan nyata. Pada kayu nyatoh hal tersebut, walaupun cenderung meningkatkan retensi, peningkatannya tidak menunjukken perbedaan nyata.

Dalam kayu nyatoh yang diawetkan dengan konsentrasi larutan lima persen penambahan lama rendaman dingin tidak dapat meningkatkan retensi bahan pengawet BFCA secara nyata. Untuk kayu nyatoh dengan konsentrasi sepuluh persen den kaya perupuk yang diawetkan dengan kedua konsentrasi larutan ditemukan lama readaman yang dapat meningkatkan retensi bahan pengawet BFCA dengan perbedaan nyata, yaitu pada kayu nyatoh dari lama rendaman dingin dua hari menjadi delapan hari, dan untuk kayu perupuk pada konsentrasi lima persen dari dua dan empat hari menjadi delapan hari, sedangkan pada konsentrasi sepuluh persen dari lama rendaman dua hari menjadi empat, enam dan delapan hari;serta dari empat hari menjadi enam dan delapan hari. 
Persyaratan minimum retensi bahan pengawet BFCA yang digunakan dalam penelitian ini untuk pemakaian kayu di bawah atap dan di udara terbuka tanpa kontak tanah masing-masing $6 \mathrm{~kg} / \mathrm{m}^{3}$ dan $8,6 \mathrm{~kg} / \mathrm{m}^{3}$, dengan penetrasi $10 \mathrm{~mm}$ (Martawijaya dan Abdurrohim, 1984; Standar Kehutanan Indonesia, 1987). Penetrasi yang diperoleh pada setiap bagan pengawetan yang digunakan dalam penelitian ini mencapai 100 persen, sehingga persyaratan untuk kedua tujuan pemakaian dapat terpenuhi.

Berdasarkan nilai rata-ratanya, persyaratan retensi untuk pemakaian di bawah atap tanpa kontak tanah pada kayu nyatoh yang diawetkan dengan konsentrasi lima persen dicapai pada lama rendaman dingin delapan hari, sedangkan dengan konsentrasi larutan sepuluh persen mulai lama rendaman dua hari. Pada kayu perupuk dengan konsentrasi larutan lima dan sepuluh persen masing-masing dicapai mulai lama rendaman dingin empat dan dua hari. Kayu nyatoh yang diawetkan selama delapan hari dan kayu perupuk dengan empat hari, serta kayu perupuk yang direndam selama enam hari, dengan konsentrasi larutan lima persen masing-masing terdapat tiga dan dua contoh uji yang tidak memenuhi persyaratan retensi. Untuk itu maka bagan pengawetan yang dianjurkan bagt kayu nyatoh yang dipakai di bawah atap tanpa kontak tanah adalah direndam selama dua hari dalam larutan dengan konsentrasi sepuluh persen. Bagi kayu perupuk sebaiknya diawetkan selama delapan hari dengan konsentrasi larutan lima persen dan memakai konsentrasi larutan sepuluh persen selama dua hari.

Untuk pemakaian kayu nyatoh di udara terbuka tanpa kontak tanah, berdasarkan nilai rata-ratanya, persyaratan retensi dicapai pada konsentrasi sepuluh persen mulai lama rendaman enam hari. Pada kayu perupuk dengan konsentrasi larutan lima persen dicapai dengan lama rendaman delapan' hari, tetapi dengan konsentrasi sepuluh persen mulai empat hari. Pada kayu nyatoh yang diawetkan selama enam hari dengan konsentrasi larutan sepuluh persen dan pada kayu perupuk yang direndam delapan hari dalam larutan lima persen masing-masing terdapat sebuah dan dua buah contoh uji yang tidak memenuhi persyaratan. Dengan demikian kayu nyatoh dan kayu perupuk yang dipakai di udara terbuka tanpa kontak tanah sebaiknya direndam dalam larutan dengan konsentrasi sepuluh persen masing-masing selama delapan dan empat hari.

Berdasarkan uraian tersebut di atas, kedua jenis kayu yang diteliti dapat diawetkan secara rendaman dingin memakai bahan pengawet BFCA dengan bagan pengawet yang digunakan dalam penelitian ini. Bagan pengawetan yang dianjurkan tercantum dalam Tabel 4.

Tabel 4. Bagan Pengawetan Secara Rendaman Dingin yang Dianjurkan pada Dusa Jenis Kayu

Table 4. Cold Soaking Schodule Suggested for Two Wood Species

\begin{tabular}{|c|c|c|c|}
\hline $\begin{array}{l}\text { Joais bayu } \\
\text { (Wood spectes) }\end{array}$ & $\begin{array}{l}\text { Pomalaien } \\
\text { (Uses) }\end{array}$ & $\begin{array}{l}\text { Rendaman dingin, hari } \\
\text { (Cold soaking, day) }\end{array}$ & $\begin{array}{c}\text { Koneontradi, } \% \\
\text { (Concentradion, \%) }\end{array}$ \\
\hline \multirow[t]{2}{*}{ Nyrloh (Palageduen ep.) } & $\mathbf{A}$ & 2 & 10 \\
\hline & B & 8 & 10 \\
\hline Poruput (Solenospermiman sp.) & $\boldsymbol{A}$ & 8 & 5 \\
\hline & $\mathbf{A}$ & 2 & 10 \\
\hline & B & 4 & 10 \\
\hline
\end{tabular}

Kelorenean (Remartos) : $\mathbf{A}=$ dibawah atap tanpe bontak tunah

$$
\text { - (inder roof without grovend contact) }
$$

(in the open alr without growed conlact)

For. Prod. Res. J. Vol. 11 No. 8 (1993)
Nilai pengembangan rata-rata contoh uji kedua jenis kayu setelah diawetkan dengan bahan pengawet BFCA, tercantum dalam Tabel 2. Dibendingkan dengan tebal dan lebar kayu yang diawetkan, maka pengembangan yang terjadi relatif kecil, sehingga mungkin tidak menjadi masalah di dalam penggunaan sebagai moulding.

\section{KESIMPULAN}

Dari hasil penelitian dua jenis kayu bentukan dengan bahan pengawet BFCA secara rendaman dingin; dengan memperhatikan persyaratan minimum retensi dan penetrasi untuk pemakaian kayu di bawah atap dan di udara terbuka tanpa kontak tanah, dapat diambil kesimpulan berikut :

1. Jenis kayu tidak berpengaruh nyata terhadap retensi bahan pengawet BFCA. Konsentrasi larutan dalam jenis kayu yang sama berpengaruh nyata terhadap retensi, sedangkan lama rendaman dingin dalam jenis kayu dan konsentrasi larutan yang sama menunjukkan pengaruh sangat nyata.

2. Penetrasi bahan pengawet BFCA pada semua contoh uji mencapai 100 persen, yang berarti semua potongan melintang contoh uji secara mudah dapat ditembus bahan pengawet.

3. Kayu nyatoh, berupa lis, yang dipakai di bawah atap tanpa kontak tanah dapat direndam selama dua hari dalam larutan dengan konsentrasi sepuluh persen, sedangkan kayu perupuk dapat direndam selama delapan hari dengan konsentrasi larutan lima persen atau memakai konsentrasi larutan sepuluh persen selama dua hari. Untuk pemakaian kayu nyatoh dan perupuk di udara terbuka tanpa kontak tanah dapat direndam dalam larutan dengan konsentrasi sepuluh persen masing-masing selama delapan dan empat hari.

4. Nilai pengembangan rata-rata pada kedua jenis kayu setelah diawetkan bahan pengawet BFCA relatif kecil dibandingkan dengan tebal dan lebar kayu, sehingga mungkin tidak menjadi masalah di dalam penggunaannya.

\section{DAFTAR PUSTAKA}

Martawijaya, A.; I. Kartasudjana; K. Kadir dan S.A. Prawira 1981 Atlas kayu Indonesia. Jilid I.

.; I. Kartasudjana; Y. I. Mandang; S.A. Prawira dan K. Kadir. 1989. Atlas kayu Indonesia. Jilid II.

-..-- dan S. Abdurrohim. 1984. Spesifikasi pengawetan kayu untuk perumahan. Pusat Litbang Hasil Hutan. Edisi III.

Standar Kehutan Indonesia. 1987. Pengawetan kayu untuk perumahan dan gedung. SKI. C - m - 001. 1987.

Steel, R. G. D. and J.H. Torrie . 1960. Principles and procedures of statistic. McGraw - Hill Book Co. Inc. New York, Toronto, London. 